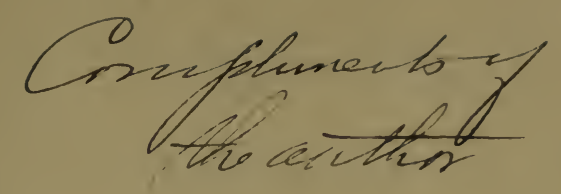

\title{
A COMPARISON OF THE RESPONSES OF SESSILE AND MOTILE PLANTS AND ANIMALS
}

PROFESSOR VICTOR E. SHELFORD

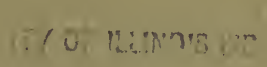

- MOV 251916

NEW YORK

1914

[Reprinted without change of paging, from the AMERICAN NATURALIST, I914.] 



\title{
577.5 \\ REMOTE STORAGE
}

[Reprinted from The american Naturalist, Vol. XLVIII., Nov., 1914.]

\section{A COMPARISON OF THE RESPONSES OF SESSILE AND MOTILE PLANTS AND ANIMALS}

\author{
PROFESSOR VICTOR E. SHELFORD,
}

\section{UNIVERSITY OF ILLINOIS}

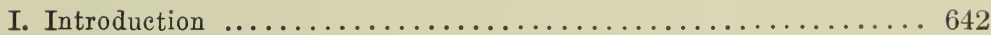

II. Basis of Discussion ............................ 642

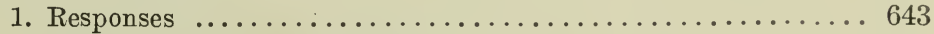

2. Sessile and Motile Organisms .....................6 644

3. The Individual and its Relation in Colonies and Groups ...... 644

(a) Animals and Plants made up of Single Individuals .... 644

(b) Colonial or Multiple Individualed Plants and Animals. 645

i. Numbers of Individuals ................ 645

ii. Stems ............................ 646

iii. Metabolic and Reproductive Relations of Individuals ...........................6. 647

(c) Response of Motile Organisms ................ 649

i. Movements .......................... 649

ii. Structural Response .................. 650

(d) Response of Sessile Organisms ................... 651

i. Structural Responses ..................661 651

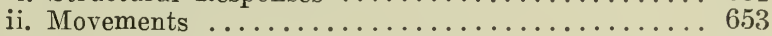

(e) Behavior of Sessile-motile Organisms ..........66 653

$(f)$ Response and Taxonomy of Sessile Organisms ........6 653

III. Parallelism between Sessile and Motile Organisms with reference

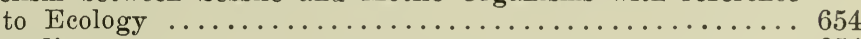

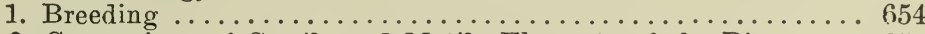

2. Comparison of Sessile and Motile Elements of the Biota .... 655

3. Sessile Motile Organisms in Ecological Succession ........ 656

IV. Influence of Response Phenomena upon Biological Theory and Con-

troversy ................................657

1. Teleological View ..........................657

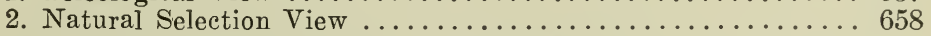

3. Supposed Non-inheritance of Response and the Germ Plasm

Doctrine .................................. 660

4. Influence of the Study of Response on Present-day Biological

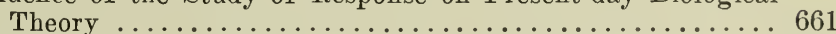

5. Aspects of the Untenability of the Germ Plasm Doctrine... 662

6. Measure of Values in Biological Science ................. 664

7. Summary and Conclusions ..........................669

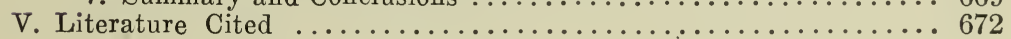




\section{INTRODUCTION}

During the past few years the attention of biologists has turned more and more from those phenomena which were supposed to be comparatively fixed, to responses to stimuli. Physiologists have long been concerned with the mechanism of response; psychologists are interested in its modification. Geographers, climatologists and ecologists have recently turned their attention to responses in natural environments and zoologists have become interested in response, particularly from the point of view of its specificity. In these quite independent investigations and compilations there has been little attempt at analysis with a view to determine legitimate lines of comparison among the exceedingly diversified types of organisms which have been investigated, and some confusion has resulted. For example, since the more obvious responses of plants are structural, persons not familiar with comparable phenomena among animals have made erroneous comparisons of sessile plants and motile animals. This paper is written to present in as nearly uniform terms as practicable $(a)$ analysis of kinds or aspects of response, $(b)$ justifiable kinds of comparison, and $(c)$ the bearing of response phenomena on biological theory and controversy. It aims to show that the numerous kinds of response are reducible to a few simple types common to both plants and animals, and that the failure to consider all types has been responsible for confusion and various one sided theories. It further aims to show that study of response during the past few years has led to an unusual broadening of our conceptions.

\section{BASIS OF DISCUSSION}

As a basis for discussion we must first have a clear understanding of the character and definition of response. Secondly, we must determine what constitutes an individual in those plants and animals that are made up of repetitions of parts. Thirdly, we must note whether or not the organism is sessile or motile, capable of playing the part of either, or colonial pelagic. 


\section{Responses}

The word response is used in various slightly different senses. In general it refers to more complex and timerequiring phenomena than "reaction." In geography the term has been used (Goode, '04) to cover all changes in culture supposed to be produced by climate or other geographic conditions. It is also applied by geographers and geologists to changes in the physical characteristics of man (evolution) which Goode ('04) has stated are slower than the cultural responses. In general botanists have used the term to cover changes of plant structure and function induced by external conditions. Cowles ('11), however, uses the word "reaction" to cover these phenomena. Coulter ('09) used the term response as synonymous with adaptation in plants. Zoologists have used the term to apply to changes in animals due to external conditions, but with little agreement as to what is to be included. We will use it here to include reactions, changes in functions, structure, color, induced by external conditions either directly or indirectly, without regard to how simple or how complex the processes involved may be. ${ }^{1}$ The length of time required to bring the changes about may arbitrarily be taken as not exceeding the time required to breed five to ten generations of the species concerned. All organisms respond to stimuli because each stimulus acts upon some internal process. Strictly speaking, the response is the change or changes in the physical or chemical processes of the organism (or the part or parts concerned) which results from the disturbance.

Those things which we commonly see and term response are often the later and less important phases of the disturbance. The striking phases of responses of motile organisms are usually movements which follow closely upon stimulation. In sessile organisms the noticeable responses often appear only after a considerable period. In both sessile and motile organisms some responses are IX.

1 For good representative bibliography see Adams, '13, Ch. VIII and 
not evident because they concern internal, chemical and physical processes which affect neither form nor movement. Changes in the enzymes secreted by digestive glands, which accompany changes in food (Jennings, '06, p. 347), are examples. While thus recognizing that responses are concerned primarily with internal processes, we must of necessity refer chiefly to the external phases.

\section{Sessile and Motile Organisms}

Sessile organisms are those which are sedentary in habit, whether attached or possessing slight powers of locomotion. Motile organisms are those that habitually move about. Vagile or creeping forms as well as swimming, walking, flying, burrowing types are included. Most sessile animals are capable of moving their parts, while only a few sessile plants possess this capacity, and these only to a slight degree.

There is no sharp distinction between sessile (sedentary) and motile organisms. Every possible gradation exists between fixed non-motile types as trees on the one hand and the pelagic fishes on the other. It is the extremes which we will compare.

\section{The Individual and Its Relations in Colonies AND GRoups}

The following comparison of animals and plants is an attempt to distinguish potential or incomplete individuals in colonial organisms and compound organisms which, while not commonly recognized as colonial, are made up of incomplete individuals.

\section{(a) Animals and Plants made up of Single Individuals}

The vast majority of animals belong here. Most protozoa, solitary sponges, solitary hydroids, sea anemones, worms not preparing for asexual division, echinoderms, mollusks, arthropods and vertebrates. Only single-celled plants, young seedlings and possibly a few adults of multicellular plants which possess but one growing point 
(exclusive of roots) belong in this group. Single individuals as described here are the basis for determining what shall be called individuals in colonial and compound types.

\section{(b) Colonial or Multiple Individualed Plants and Animals}

A number of animals and the vast majority of the plants belong here. The group can be roughly divided into two types, $(a)$ those having a chain or plate arrangement of incomplete individuals and $(b)$ those having a branching or tree-like arrangement. The groups of incomplete individuals of type $a$ occur among the Protozoa, worms undergoing asexual reproduction, many of the Bryozoa and some of the Tunicates; both sessile and pelagic (plankton) forms occur. On the plant side type $a$ includes plate-like colonies of algæ, filamentous algæ, some thallose plants and probably some of the fungi, though the great multiplicity of forms makes the separation of this group from the branching tree-like types, difficult.

Type $b$ includes some of the colonial Protozoa, the majority of the sponges, hydroids, corals and the branching Bryozoa. The algæ, fungi, mosses, ferns and flowering plants are all represented. The colonies are usually attached to the substratum (sessile).

i. Numbers of Individuals.-Among the animals the number of so-called zooids is the number of incomplete individuals. In the sponges there are as many zooids as there are excurrent openings (osculæ) (Minchins, '00, p. 91). Zooids usually possess a mouth opening and organs for securing food, though in some cases they mav be specialized for reproduction, defence or locomotion as in some of the Cœlenterates. Among the colonial plants there are as many incomplete individuals as there are buds or growing points (vegetative regions). There are no regularly occurring organs in animals, strictly comparable to leaves. However, any organs such as tentacles, gills, etc., which secure or absorb nutriment may be re- 
garded as analogous to leaves. Each potential bud with its leaf may be compared to a zooid. In comparing plants and animals, roots can perhaps be compared with the holdfast organs of hydroids. In both groups, roots and root-like organs are individuals of a very low order of individualization and of a type not well represented among animals. The holdfast organs of animals are not important absorbers of food and water.

ii. Stems and Other Connecting Organs (Conducting Tissues).-The most striking difference between the incomplete individualed or colonial plants and colonial animals is the presence in the former of specialized stems and highly complex conducting tissues (Cowles, '11; Pütter, '11, pp. 361-66). The conduction of food materials from the root to other parts of the plant and from the leaves to the root is a functional necessity not paralleled even in those colonial animals showing the greatest division of labor. In animals stems are relatively undifferentiated and are often made up of living, relatively unspecialized zooids, as, for example, in many Bryozoa such as Crisis. The tendency to cauliflory in some plants and the ability of cambium to produce shoots and of the stems of most hydroids to produce individuals indicates that such a condition may be potentially present in all. In stalked Protozoa the stems are solid, while in most Cœlenterates they are tubes, usually simple though sometimes complex, made up by mere elongation and branching of the stock of the simple single forms such as the Hydra. The lumen is usually ciliated and makes possible a transfer of material which renders practicable such division of labor as occurs in this group (Pütter, '11). In the Bryozoa the different zooids have their body cavities joined in the simpler forms merely as a branching lumen of the main wall of the colony; in others by small openings the more specialized of which are sieve-like plates (Harmer, '01, pp. 471 and 496; Delage and Herouard, '97, Vol. 5, p. 62).

The connection between the individuals of the tunicate colonies is often very complex, due to the fact that in the 
most complex types the stolon (stem) gives rise to new individuals and possesses all the layers of cells which take part in forming them. The connection between different individuals differs in different groups and is determined by the particular mode of asexual reproduction. As the individuals are quite independent of one another in function, these connections do not have the same significance as in plants. Even where there is a common blood circulation, as for example in the Clavellinide (Harmer, '04, p. 71), there is no noteworthy division of labor.

iii. Metabolic and Reproductive Relations of Individuals.-The flat worms at certain times consist of chains of zooids at various stages of development and with various degrees of independence. Child ('13) has found that these chains of zooids present a series of gradients in rate of metabolic reaction. The rate is highest at the anterior end of the whole chain and decreases toward the posterior end, not uniformly, however, for the rate is lower immediately in front of each head region than it is in the head region itself. A gradient is present in the axis of each zooid. The most anterior head dominates so long as the chain remains intact. In the corals certain zooids dominate (Wood-Jones, '11) over the others. Some types have a single dominant zooid and some more, while in other cases all are equal.

Among plants whose form is that of a chain or a plate the individuals are less closely bound together and dominant vegetative regions are probably less well developed. In the branching types, dominant vegetative regions occur (Cowles, '11, p. 747 ; Goebel, '00, Vol. I, p. 206). In the conifers, for example, there is a leader, a dominant growing region at the tip of the main stem just as in certain madrepore corals (Wood-Jones, p. 83). Other plants like the elm have several vegetative regions which dominate over others, as they do in the branching madrepores.

Growth form or colony form varies according to certain laws dependent, in part at least, upon the metabolic 
relations of individuals. Thus Wood-Jones says of the corals-

a colony may grow according to five different types of vegetative growth . . . it may grow as (1) a spherical mass, (2) an enerusting layer, (3) a free plate, (4) a branching tree-like growth, or (5) a mere amorphous lump.

He further notes the division of all the corals into two groups of normal growth-forms; for all the zooids may take an equal share in the asexual reproduction or, again, some may be of greater importance than others, and the asexual reproductive functions may be lodged in a very few individuals only. Considering the first division (all zooids taking equal share, the principal types of budding vary from each other in the actual site of origin of the daughter zooid from the parent, in the degree of final separation of the two zooids, and in the thickess of the intervening partition between the two zooids. The amount of rising above the general surface by each individual zooid is likewise subject to variation.

Turning now to the corals that constitute the second class (some zooids of greater importance than others) which in the words of Wood-Jones have some of their units specialized as active agents of growth,

it is at once seen that the possibilities of variation of normal vegetative habit are greatly increased. All the elaborate branching forms, plates and leaf-like growths belong to this class; and all are evolved by special peculiarities of the growing point. The zooids that constitute the growing point may take various forms; they may be arranged as a cluster, as a creeping edge, or as many varieties of terminal shoots of branches.

In the first instance, it is necessary to draw very sharp distinctions between two subdivisions of this group. In Group 1 come all those forms like Montipora, whose distal zooids are the newest formed members of the colony; and in Group 2 are included the Madrepora, whose distal zooid is the most ancient individual in the whole group.

In dealing with Group 1 many forms have to be considered, for when the youngest are the active zooids their growth cluster may be variously disposed, and on its disposition the resulting vegetative form entirely depends.

In Group 2, however, this state of things is entirely altered, for there one zooid, which is situated at the extremity of the stem, and which I 
shall call throughout the " dominant apical zooid," constitutes the growing point; and this zooid is the parent of the entire colony.

Various writers make comparable statements or show comparable principles among hydroids (Motz-Kossowska, '08) and Bryozoa (Davenport, '91, et al.) and among plants (Goebel, '00). Of the colony form of the tunicates Herdman ('04, p. 82) says:

The marked differences in the appearance of the colonies of compoumd Ascidians is largely due to the methods of budding; even in those of stolon type where the budding is practically the same in essential nature, the results may be different in superficial appearance, according as the buds are formed on a short stolon close to the parent body, or from the extremity of the post abdomen or from the long epicardiac tube which may extend for some inches from the ascidiozooid.

Thus we conclude that the innate causes of different growth-forms (colony forms) of colonial organisms are (a) the mode of division of the zooids or vegetative regions, $(b)$ the ratio of stem elongation to number of zooids or buds produced or uniformity or lack of uniformity of stem elongation (Wood-Jones, p. 76) closely related to $(c)$ the presence or absence, number, position and region of influence of the dominant growing regions or dominant zooids, and $(d)$, in some cases, the grand period of growth and the length period of the intornodes (Johnson, '11). The innate tendencies are thus reducible to a few principles applicable to both plants and animals.

\section{(c) Responses of Motile Organisms}

i. Movements.-In motile organisms the most striking responses are changes in position brought about by movements usually more or less random, and which bring the organism into various conditions one of which usually relieves the disturbance. The organism resumes normal activity in conditions which brought the relief (Jennings, '06). These conditions are not necessarily advantageous, but are usually so when the stimuli are those encountered in nature (Mast, '11). Behavior of motile organisms is also modified by repetition of action even in animals as low in the animal series as the Protozoa (Holmes, '11). 
Jennings ('06) has quoted various botanical workers' observations on motile plants the behavior of which probably follows the general laws governing the behavior of motile animals. As a result of the quick behavior responses of motile organisms, their distribution at any given time is a better index of the conditions at that time than the distribution of sessile organisms, because when the conditions at a given point become unfavorable the motile organisms usually move to another situation, while the sessile forms remain and perhaps die.

ii. Structural Responses.-Among motile animals, structural and color changes occurring as a response to environmental conditions (stimuli) are usually not of importance to the organism concerned. The color differences induced in Lepidoptera by heat and cold (Stanfuss; Fischer) and the structural differences in Crustacea such as were brought about in Cladocera by Woltereck, and other modifications brought forward recently, are usually of no known advantage or disadvantage to the animals concerned (Bateson, '13, Ch. IX and X). Such responses in color and general form do not ordinarily take place in adults subjected to such conditions. The striking structural responses of motile animals are often responses to the organism's activity. The use and disuse phenomena of the Lamarckians, the increase in size and form of muscles, thickening of skin in man and mammals, are well-known examples of a type of responses which have influenced zoological speculation. Child ('04) controlled the form of Leptoplana by controlling activity. Holmes ('07) found that the movements of pieces of Loxophyllum have an important part in shaping the general outline of the bodies of the resulting forms. The general forms of motile animals are correlated with their activities but whether form or structure correlated with it appeared first in the course of evolution has been the subject of considerable fruitless speculation. 


\section{(d) Responses of Sessile Organisms}

i. Structural Responses.-The striking phases of responses among colonial sessile organisms are often changes in form and structure, or the relative position of the parts. The changes in structure or position of parts are not necessarily advantageous or useful, but are usually so when the stimuli are those commonly encountered in nature (Cowles, '11; Loeb, '06, p. 124; WoodJones, '11; Ch. VIII). Indifferent and detrimental responses are oft $\mathrm{n}$ given under experimental conditions an $\mathrm{x}$ no doubt the absence of such variants among sessile animals collected in a wild state is due in part to the failure of such organisms to survive. A few sessile colonial organisms such as cacti (Cowles, '11) show little or no plasticity.

Among sessile animals, the observations of WoodJones form the best examples of response. He found that the branching type of corals dominated in barrier pools, tall slender non-branching types in deep water, and massive boulder types on surf beaten shores. Thus he figures similar colonies of each of three genera which, while possessing certain peculiarities of their own, are in general agreement as to growth form just as sessile plants usually are; and this in part for comparable reasons. Thus various conifers occur as Krummholz in the high mountains, due to severe conditions (Cowles, '11, p. 732), wind, snow, and in part to the injury of terminal growth regions of the main stem which gives rise to lateral branches. The boulder-like corals with the zooid at the same level occuriing on the surf-beaten shores of coral islands are due, in the case of Madrepora, for example, to repeated injury of the terminal dominant zooids. Conifers in protected situations often grow into tall slender trees comparable with the (deep) still-water corals. The barrier pools afford conditions where the terminal buds are less often injured than in the surf and the tree-like branching corals result from minor injuries to dominant zooids. 
Wood-Jones finds further that still-water corals are less strongly calcified than those in rough water, the strains producing increased secretion analogous to increased tissue production as a result of mechanical strains in plants (Cowles, p. 669). Corals show different kinds of growth under different environments particularly when injured. The new part may be different from the rest and adjusted to the environment thus making it appear as though two "species" occurred in the same colony. The mode of division of the zooid is also different under different conditions. Plants show similar variation with changes of conditions, particularly in the leaves which are divided in submerged portions of amphibious plants and entire in the emerging portions (Cowles, '11, p. 595).

As has been noted, there is nothing in sessile animals that is more than roughly analogous to leaves. Leaves show marked structural differences on different parts of the same tree where the environmental conditions are different, as, for example, in the differences which occur between the upper and lower portions of a forest tree. While there are, no doubt, differences in similar details (histology) in the organs of display in different parts of the same colony of sessile animals, little or nothing has been done upon them. As a further indication of the prevalence of structural response in sessile organisms of the hydroids Hickson states that there is probably but one species of Millepora which occurs in a large number of growth forms. The commercial sponges (Moore, '08) and common freshwater sponges and polyzoa show many different forms under different environmental conditions.

The major differences in growth form induced by external stimuli in colonial organisms result from modifications of the rate and character of growth with respect to the four innate tendencies toward various growth or colony forms discussed above, and which may be briefly enumerated as follows: (a) mode of division, (b) amount of stem elongation, $(c)$ influence of dominant regions and 
(d) grand period of growth and the length of period of internodes.

The principles are concerned with asexual reproduction and apply to motile organisms only exceptionally as for example in the case of colonial pelagic forms. The laws are applicable to both plants and animals.

ii. Movements.-Movements of sessile animals are usually contractions or extensions of parts or of the entire body. Tentacles and comparable organs are capable of movements for securing prey. Such organs often tend to wrap about objects which are in motion. Many sessile animals are capable of opening and closing a mouth opening and of bending or twisting the entire body. Plants possess a comparable capacity only occasionally.

\section{(e) Behavior of Sessile Motile Organisms}

Most sessile animals are capable of some movement and react by contraction of parts. The reactions may be modified by repeated stimulation (Jennings, '06) and usually by physical factors. Some animals, as Hydra, Stentor and many others are both sessile and vagile or free-swimming, and show different types of behavior when attached and when free. Jennings states that such protozoa have a more complex behavior than motile forms. This is due to their combining the types of behavior of sessile and motile animals.

\section{(f) Response and Taxonomy of Sessile Organisms}

Hickson ('98) has stated that there is but one species of Millepore and believes that sex organs will be found to be the best taxonomic characters. Wood-Jones states that there are far fewer species of corals than has formerly been supposed, and states further that growth form can not be used to distinguish species. Among fresh-water sponges and Bryozoa reproductive bodies (gemmules and statoblasts) have been found to possess satisfactory taxonomic characters. This is a situation quite parallel with that in plants where reproductive 
organs are used as classification characters. The ideas of the reproductive organs of plants are now at the "fixity" stage which on the animal side is paralleled by the idea of fixed tropisms and fixed instincts, of a few years since. Variability of tropisms is now well recognized and reproductive organs in plants are being found plastic, as those of animals will probably be found also.

III. PARALLELISM BETWEEN SESSILE AND MOTILE ORGANISMS WITII REFERENCE TO ECOLOGY

From a summary of the considerations above it will be seen that for practical comparison the division of organisms into plants and animals may be abandoned and only reference to sessile and motile organisms made. We may now turn to a discussion of a few general principles making the division into sessile and motile organisms only. The behavior of motile organisms is plastic. There are innumerable cases of modification of reaction by variations of physical factors (Jennings, '06; Loeb, '06; Mast, '11). If for purposes of discussion we put the usual "normal" reactions of motile animals over against "normal" structure of sessile animals, we note that the behavior response of the former parallels the structural response of the latter.

\section{Breeding}

Motile Organism

(a) The breeding activities take place within narrower limits than any other activities. Merriam, '90; Herrick, '02; Reighard, '08; Shelford, '11 $a, b, c$, '12a, $b$.

(b) The selection of breeding place and breeding activities, including first activities of the young, are governed by the same general laws as other activities.
Fixed (Sessile) Organisms

(a) Breeding and other activities within same limits, except that dispersal may take place over wide areas through detachability of seeds and other reproductive bodies.

(b) Less marked because a selection of abode by sessile organisms takes place through the behavior of motile young stages or through wide dissemination of nonmotile bodies by wind (etc.) with growth under favorable conditions and failure elsewhere. 
(c) The breeding activities are probably least modifiable and least regulatory. (c) The reproductive organs and early embryonic stages are less modifiable than the vegetative parts.

$(a, b, c)$ The maple tree, a sessile organism, is entirely stationary in its adult stages. The seeds are blown by the wind. One would not accomplish much in the study of ecology by studying the distribution of the seeds of the maple, or, on the other hand, by the study of the distribution of adult birds, without some further discrimination.

Sessile organisms are not difficult to associate with their proper environmental conditions in their adult stages. As we proceed in our study to forms which can move readily and rapidly, the difficulty of associating them with their definite environmental conditions increases. Sessile organisms have stages which are small and capable of easy dispersal, as in the case of the maple. Sessile marine animals and some sessile plants frequently have motile forms in young stages. In these motile stages they are governed by the same laws as other motile organisms. The conditions under which the motile stages develop into the sessile forms are crucial.

Most fresh-water forms and some marine forms of sessile organisms are without the free-swimming stage, and they produce non-motile stages physiologically comparable to the seeds of higher plants. The winter bodies (statoblasts) of the Bryozoan (Pectinatella) common near Chicago, and which is a strictly sessile organism, are comparable to seeds and probably require "ripening" by cold, just as do many seeds and the reproductive bodies of some other species of the same group. Organisms which are highly motile in the adult stages are not motile in the egg and young stages. The eggs and young of birds, for example, do not move about, yet birds are the most motile of all animals.

\section{Comparison of the Sessile and Motile Elements of THE BIOTA}

(a) The motile organisms of a

(a) The sessile organisms of a given habitat usually react simigiven habitat (particularly plants) 
larly to two or more stimuli not differing greatly in intensity from their optimum, $i$. e., the percentage of positive or negative trials is essentially the same for standard intensities. There is also probably . similarity in the rates of metabolism, etc.

(b) The specificities of behavior such as the mode of moving the organs, e. g., of locomotion, and in some cases the combined results of different behavior reactions are similar and hence are ecologically equivalent. The size and efficiency of the organs are also involved. usually show similar functional rates, such as similar rates of transpiration among sand dune plants.

(b) The various structural devices which meet the conditions of the environment are ecologically equivalent.

A testing, for example, of the rheotaxis of a large number of brook-rapids animals has shown them to be strongly positive, and when active individuals only are considered the percentage of positive trials is very similar for the entire rapids community. Likewise they are in accord in their avoidance of sand bottom. Many of the animals have special means of attachment which may be brought into play with speed.

As has already been pointed out elsewhere, ecological equivalence is illustrated here. The darters (fish) are strong swimmers and are able to live in rapids by virtue of their swimming powers and positive reaction, while snails meet the same general conditions through positive rheotaxis and the strong foot which enables them to hold to rocks.

\section{Sessile and Motile Organisms in Ecological SuCCESSION}

(a) Ecological succession is succession of ecological (physiological) types orer a given area, due to changes of conditions which both cause migration of physiological types and transformation of such types as remain (Shelford, '11 $a$, '11b, '11d, '12a, '12b and citations). Changes of conditions are geographic, i. e., physiographic, climatic, 
etc., and biological (due to organisms). Sessile plants are the chief biological cause of succession on land and in fresh water, while sessile animals are the chief biological cause in the shallow portions of the sea, especially in coral reef regions (Wood-Jones, '11). Sessile organisms are more important causes of succession than motile ones because they $(a)$ build up the substratum with detritus and skeletons, $(b)$ interfere with the movement of the surrounding medium, $(c)$ cut off light from the substratum where other organisms must reside and their own young secure foothold, and $(d)$ they usually affect their own environments with excretory products more than do motile organisms. In general we recognize ecological succession of motile animals through the differences of behavior which accompany changes in conditions. The differences are physiological; differences in behavior are the easiest index of the physiological condition. The character of nests, burrows, etc., are often good indicators also.

IV. INFLUENCE OF RESPONSE PHENOMENA UPON BIOLOGICAL THEORY AND CONTROVERSY

A glance at some aspects of biological speculation since before the publication of Darwin's "Origin of Species" is essential to our understanding of the attitude of biologists until recently, toward responses.

\section{Teleological View}

In the matter of animal behavior response, the earlier workers interpreted the reactions as intelligent and purposeful, ascribing human sensations, etc., tơ animals as low in the scale as protozoa. This teleological tendency was paralleled on the plant side by the idea of purposeful adaptive responses. Many common plants respond (structurally) readily to environmental conditions. As has been noted, the commonest of the surviving responses of the wild state are apparently advantageous. This led some botanists to a Lamarckian teleological conception of response, perhaps best represented by Kerner and 
Oliver's work on the natural history of plants. According to this view, responses are advantageous and for the purpose of preserving the plant. Thus response and adaptation become synonymous (Coulter, '08), a usage quite inapplicable to animal structure. At the beginning of the recognition of the response phenomena of corals Wood-Jones takes essentially the view of adaptation which botanists have tried and rejected.

Lamarck, who was for many years engaged in botanical work, must have noted many cases of advantageous structural response in plants. Later he undertook the study of invertebrates which show great plasticity, and was naturally much influenced in the development of his theory of transmutation of species by the response phenomena in the plastic organisms which he studied. Thus the responses of motile (as well as sessile) organisms which result from their own activities or the action of their environments formed an important feature of Lamarck's (Packard, '01; Cope, '96) theory of transmutation of animal species. His theory is clearly in accord with the material he studied most. The nature of his contention and various well-known circumstances caused his ideas not to be accepted.

\section{Natural Selection View}

Characters used in classification of motile animals before and since the time of Darwin are quite frequently adaptation characters. Thus the large pectoral fins and absence of an air bladder are characteristics of an entire group of fishes, the darters. The divided eyes of the Gyrinida, which swim at the surface of the water, are so adjusted that one half looks downward into the water, and the other outward into the air. This character combined with the paddle-like hind legs would have served to distinguish the family. Again larvæ with a head and thorax modified to fit a circular burrow and with hooks on the dorsal surface of the fifth abdominal segment, which is supposed to be an adaptation to prevent the animals 
from being drawn from their cylindrical burrows by their prey, could serve to distinguish the entire family of Cicindelide (tiger beetles). Such cases might be multiplied indefinitely.

Following Lamarck came Darwin, who, being more particularly a zoologist, was probably (proportionately, at least) less familiar with structural response phenomena. He was apparently impressed with the "fixity" of the so-called adaptation characters in motile animals, and with the fact that they are often family, generic or specific characters. With the assumption that they originated in the environment in which they are now found, Darwin and his followers on the zoological side credited "natural selection" of structural characters with the origin of species. Though broader than Lamarck, this important feature of Darwin's theory was quite clearly drawn from data on motile animals. After the acceptance of Darwin's theory, biologists were for many years engaged in elaborating the ideas of phylogeny and natural selection by working out recapitulations and homologies and by pointing out cases of adaptation. The investigation was largely confined to the highly individuated animals. The morphological method of this period, which indeed has still continued in use among a minority of zoologists and which finds a parallel in the recent morphological study of the sex organs of plants, belongs to descriptive rather than to analytical science. Since its conclusions are often based upon the arrangement of species or of stages in development into series chosen by the investigator, it is a method which often allows free play of subjective fancy. Thus unconsciously experimental study of modification by environment became more and more neglected, and the dominant type of investigation being such as to show only the usual course of events in development, the ideas of fixity grew more and more. Thus the fact that the external form, structure and color of animals are not easily modified without careful experimental methods, and that the structural responses of sessile animals were 
so little known, resulted in structure in animals being frequently regarded as fixed and every resemblance and peculiarity being too often regarded as significant. The explanations of supposed adaptations among animals fell largely to the theory of natural selection which was strained by some (see, for example, in Romanes, '92, p. $269)$ to explain origins in great detail, largely on the basis of the competition of species for food, etc. Explanations along this line were carried to a reductio ad absurdum as indicated by Livingston ('13) and have by no means disappeared from the scientific calendar. This tendency was less important on the plant side. More attention was given to speculation concerning adaptive response.

From a consideration of the facts just presented, we note that the characters of the two leading early view points in evolution were no doubt influenced if not actually caused to crystallize into their peculiar form by the failure of workers to recognize the entire series of phenomena which we have presented above. Thus a review of the responses of sessile and motile organisms throws much light on the influences leading to the first conceptions and later modification of these two leading doctrines. Botanists for many years dwelt mainly on the response of sessile organisms and crystallized a Lamarckian conception of the origin of adaptations through the fixing of advantageous responses as hereditary characters. During the same period zoologists essentially ignored sessile and other multiple individualed animals and their great plasticity and crystallized the Darwinian idea into Weismannian germplasm doctrine based on highly specialized single individualed animals.

3. Supposed Non-Inheritance of Response and the Germ Plasm Doctrine

The theory of the independence of the germ-plasm from the soma, and its continuity from generation to generation, was brought strongly to the attention of zoologists in 1885 by Weismann. It was the natural outgrowth of the methods and theories of the preceding period and 
was largely based upon the non-inheritance of mutilations and the fact that the germ cells of a few organisms are, morphologically, early differentiated from the soma. Turning to its influence upon ideas concerning response, we note that from this viewpoint details of structure were not of fundamental importance unless traceable to the germ plasm. Still, structural details were more important than response, because, with the exception of instincts, responses were believed to occur independently of the germ plasm and hence were of interest only on their own account. Thus the methods used in applying Darwin's theory led to neglect of experimental study of response and culminated in the extreme views of Weismann. The germ-plasm theory or the ideas of heredity which are associated with it has dominated zoological thought almost if not quite down to the present day. ${ }^{2}$

\section{The Influence of the Study of Response on Present-Day Biological Theory}

One of the most striking developments of recent years has been the discovery that behavior responses are modifiable to a high degree. Small traces of reagents reverse

2 Unconsciously suggestions of the supernatural which come up in connection with heredity and evolution have stimulated investigators to study and speculation, though they have often approached the question of heredity with an unscientific attitude. This is indicated by such statements as "I could not, however, resist the temptation to endeavor to penetrate the mystery if this most marvelous and complex chapter of life" and "the momentous issues involved" and "no more fundamental problem could well be stated" bear out this statement. The ardency which appears here and elsewhere in the discussion of scientific questions, appears to the writer to be associated with the discussion of problems which can not be referred to existing facts for solution. Few of the present generation of scientific men acquired a working knowledge of the methods of science before the age of twenty-five years, and the early habits of mind were formed in the atmosphere of the supernatural and dogmatic, which has characterized human thought for centuries. It is doubtful if the majority of us can maintain a scientific attitude for more than a short period; we must constantly come back to our tests and principles. This may account for many of the contradictions regarding scientific principles which one finds in the conversation of scientific men. When the methods of science have become the methods of society we may expect a group of scientific men far more effective than we ourselves can hope to be. 
reactions. Intelligent behavior occurs in the lower Arthropods. Even Paramocium shortens the time required to turn around in a tube, by repetition. Actions formerly regarded as instinctive now appear to be mere innate tendencies perfected by repetition. Thus the ideas of fixity have essentially disappeared from this field.

The response of organisms to injuries and the general control of form in the lower groups has done much to break down the ideas of fixity developed by Weismann and embryological schools. Thus Child, the leading American worker in this line, is able to control size, form, number of eyes in the case of Planarians. Various writers have.found modifications inherited after several generations of repeated stimulation (see Bateson, '13). The development of anti-bodies (immunity) has been shown to be a response occurring in connection with many normal processes. The discovery of responses of so many types has led to abandoning ideas of fixity even among students of embryology and genetics. Thus we note the recent decline of the doctrine of continuity and independence of the germ plasm and kindred doctrines and points of view, which constitute the central ideas of fixity. It will accordingly be profitable to consider some further facts which make the germ-plasm doctrine unnecessary.

\section{Aspects of the Untenability of the Germ Plasm Doctrine}

The presence of primordial germ plasm is assumed even in sessile colonial organisms such as plants, cœlenterates, and in flatworms, etc., where under certain conditions any small part of the body may give rise to a complete organism. Here the theory is not needed to explain the facts.

Child ('11) said:

The theory of the continuity of the germ plasm as a system, independent of the soma, except as regards nutrition, has played an important part in biological thought during the last two decades, but I am convinced that it has led in the wrong direction and that it is re- 
sponsible for many pseudo-problems of heredity and development, which on the basis of a different theory could never have occupied the attention and wasted the energy of biologists. Briefly my position is, that the gonad primordium is, at least up to a certain stage of development, physiologically a part of the individuality as are other organs, and that its further history of differentiation into male and female gametes indicates that it becomes specified in a particular direction, at least partly in consequence of its correlative environment in the organism.

The independence of the germ plasm is not well supported physiologically. Thus Wilson ('12, p. 163) says of the effect of prolonged ingestion of alkaline salts by mice:

No obvious changes were evident in the liver, kidneys, lungs, spleen and intestines but in the testes some extraordinary alterations were found. These results are of especial interest because as the cells of the testes except the basal cells are regarded by many cytologists as out of coordination with the somatic cells. As a result of these experiments it would seem that they are more susceptible to changes in reactivity than the surrounding plasma.

Dungay ('13) and authors cited have thrown comparable light on this question.

The facts of embryology themselves are but a pseudo argument in its favor. The organisms in which continuity is suppcsedly demonstrable are highly individuated and their organs highly specialized and many different organs are early separated from the common mass of cells. The germ cells thus follow the general law of development in such animals. The germ plasm is probably no more independent of other parts of the organism than is the liver or any other special tissue. "Germ plasm" and "germinal continuity," if such exist, may thus be merely incidental to the particular type of organization of the specialized individuals in which they occur.

It should further be noted that on the botanical side this doctrine of the independence and continuity of the germ plasm has received little attention and has been given little credence because "germ plasm" arises from different tissues and is neither set aside early from the soma nor is it in any other sense clearly continuous. 
Furthermore, the plasticity of plant structures made the application of the doctrine of natural selection to supposed adaptations untenable, and this type of explanation has received little more attention with botanists than have Lamarckian speculations with zoologists. The adaptation characters of plants can not ordinarily be used as taxonomic criteria (Coulter, '08).

\section{The Measure of Values in Biological Science}

One hears reference to pure science as something quite apart from applied science. It is indeed true that investigators in pure science are to some degree prompted to push forward in research by interest in the problems for their own sakes. But the human mind does not work long isolated from practical affairs or the main channels of human interest, and it is doubtful if the pure-science investigator continues long in this way. Observations are soon connected up in some way, actual or possible, with some human interest, be it as remote as the improving of human stock in remotely future generations. Thus "pure science" defined as investigation for investigation's sake hardly exists so far as the pure-science workers are concerned, but may be best defined as an indirect method of attacking problems of general importance. It differs from applied science in that application to practical problems is not its aim, though the estimated value of theories and results in "pure" science are often greatly modified by applicability to practical questions.

Certain problems and groups of facts in biology are sometimes referred to as fundamental. Some one has said that a fundamental problem is one the solution of which biologists have decided will give greatest progress. It is doubtless true that a few leaders reach such decisions with regard to particular questions, but the real causes of their general acceptance as fundamental are social and imitative. Thus when one investigator or a small group of investigators arrives at such a decision many others usually become active along the same lines largely because it is a popular topic. Thus under the influence 
of a group of investigators among whom Weismann was a conspicuous leader, problems of the germ cells, the egg's early development, and heredity, became "fundamental problems." They evidently argued that since all comes from the egg and germ cell, all must be discoverable in the egg. If germ plasm were as independent from soma, as completely insulated from environment as continuous from generation to generation as has been assumed, the study of germ plasm would be the only way to the solution of the problems of heredity and evolution. This follows no matter whether the chromosomes or almost the entire egg are credited with carrying hereditary qualities; only the postulation of continuity and independence from soma and insulation from environment are necessary. If the independence of germ plasm from soma be accepted even in a weakened and modified form it follows that studies of somatic characters can at most be of secondary importance from the point of view of heredity and evolution. Thus in some quarters the value of various lines of zoological work has been estimated largely, unconsciously, no doubt, in proportion to the nearness or remoteness of their relation to.the "germ plasm" question.

Thus it is true that in biology as in all other fields values are measured consciously or unconsciously by criteria. In recent years another better criterion of value has made its appearance among zoologists. The germ plasm criterion already discussed was primarily morphological; the second is physiological, borrowed no doubt from physiologists. It measures values on the basis of the analysis of the organisms into terms of physics and chemistry or is concerned with a mechanistic conception of life in all its manifestations. From this viewpoint the study of each and every part of the organism is important because the discovery of laws governing one part is usually or at least often of general importance. Investigations from this viewpoint have shown that the germ plasm criterion is clearly illogical in its application to the study of somatic characters because it is based upon the 
tacit assumption that the soma is governed by different laws from the living matter which makes up the germ plasm from which it arose. In other words it is assumed that the germ plasm is so different from the soma that the discovery of laws governing the soma is a type of investigation of relatively little significance.

Some criterion of values is of course necessary in science as well as elsewhere, and for the sake of argument we would be willing to accept the second when broadly stated and the first when broadened and modified so as to accord with the second as appears to be the case among certain students of genetics. In other words, problems of the germ cells, the egg, and heredity, are of much importance when the germ cells themselves are regarded as dynamic and in their relations to the dynamics of the organism as a whole.

Granting that these are true and tenable criteria of values in present-day biological science, what is to be the method of application? Should biology demand that results be of direct application to these "central" problems? One has but to look at the history of almost any branch of science to find that great, if not the greatest, advances have come through following up results at points where relations to the central problems of the period were quite unsuspected, or by the transference of methods, principles and results from one field to another where relations between the two were not suspected. Take, for example, immunity and immunization, the history of which is ably sketched by Adami ('08, pp. 451528 ). It has been known for ages that one attack of many infectious diseases yields more or less complete immunity from subsequent attacks. Thus for centuries in India and the East individuals, chiefly children, have been purposely inoculated with matter or by contact. The practise grew out of experience showing that diseases thus communicated to healthy individuals from weaker ones are less severe. In 1796 the results of Jenner on vaccination with cowpox were published. This may have influ- 
enced Pasteur, who over eighty years later laid the foundation for the modern epoch of development, by combating a plague of diarrhœa in poultry (1880). During the twenty years following, various investigators added noteworthy contributions, and about 1900 Ehrlich and Morgenroth evolved the "side-chain theory" by which a large number of possible conditions can be predicted and all the observed facts of immunity explained. While not expressed in strictly chemical terms, the theory and the experiments which support it are very important both practically and theoretically. In recent years the knowledge of immunity and comparable phenomena have been greatly extended. Various workers (Pfeffer, Vol. II, p. 262) have shown similar phenomena in the.increased resistance of plants to poisons, thus making the responses of plants and animals still more generally comparable. Most recently workers on problems such as fertilization (Lillie, '13), standing in close relation to the older germplasm' doctrine, have discovered facts belonging to this field and made use of Ehrlich's theory to explain the observations. This development has helped to confirm the conclusion of some investigators that immunity phenomena represent important features of the chemical mechanism of life. Adami has remarked,

That a plague of diarrhœa in a poultry yard, studied by a professor of chemistry, should be the seed from which has grown the vast derelopment of later years is a strange fact, but a fact nevertheless.

What was the attitude of pure science so called, of germ-plasm doctrinairies, and biologists generally during the long period which elapsed before they could make use of his results? Clearly it was one of indifference, if not disgust, toward the subject. The probable result of such attitudes on the progress of the investigation of immunity phenomena, had it not been for their immense practical significance, is clear. They could not have received their proper share of attention. Thus in the pursuit of the analysis of the chemical mechanism of life men who sought it directly have failed in this one impor- 
tant step, and the chief contribution has come from very remote indirect methods. Generally speaking the investigators who choose a direct method of attack often put themselves somewhat in the position of the chemist who would make chemical analysis of living matter when his first step defeats its own purpose by killing the substance to be analyzed. The failure of exclusively direct methods is often evident. Still the ability to obtain results by the method of direct attack, combined with a far too rare ability to tie with them indirectly obtained data, sometimes gives noteworthy contributions.

It accordingly remains to be seriously considered whether or not biology can afford to apply criteria to the measure of the values of investigation. Their application is of course largely unconscious, but the effects are not thereby modified. Noteworthy results of their application are $(a)$ concentration of work in certain lines indicated by a given criterion, and $(b)$. an actual abandoning to a large degree of remote and indirect methods of attacking the problems which the criterion involves. This means the partial abandoning of the methods for which pure science stands.

Criteria can be safely used only in a very broad general way, and in application more often to past progress than to current investigation. They are perhaps most valuable as a guide to individual investigators working on problems remote from these more or less central "pure science" questions. That some guide should be in the hands of such workers is beyond question. In the hands of those attacking the problems directly they often appear detrimental because they soon take on an extreme form and become regarded as fundamental. At this stage they are usually in need of extensive revision. If the investigator is contributing observations and details only, he is doing a great service, for such information is needed everywhere. If he is able to combine his own and others results, he almost invariably draws data from all sources, direct and indirect, far and near. Granted the 
ability to synthesize, the opportunity to use the ability sometimes comes to those who attack the so-called central problems directly. It comes equally often (we believe more often) to those who have led up to the central problem from some remote viewpoint, frequently condemned by the followers of direct method of attack. Granting the importance of synthesis, if the biologist seeks the solution of such a problem as the germ-plasm problem, he should encourage workers to start at points as remote from the subject as possible, that they may approach it with new light and from new angles.

In judging the work of another, its value should be determined more by the $(a)$ strictness of scientific method used, $(b)$ the thoroughness and completeness of the investigation, and $(c)$ (and perhaps most important of all) evidence of ability to synthesize and combine other results with his own with a view to broader generalization. It must, however, also be recognized that there are many biological problems of much human importance, which must be solved quite independently of the ideal central problems of pure science.

\section{Summary and Conclusions}

From the data presented above, we note that the doctrine of purposeful, advantageous response (including anthropomorphic ideas) arose from the uncritical nonexperimental study of the responses (structural) of sessile and (behavior) motile animals. The idea of the allsufficiency of natural selection is largely the outcome of observational study of apparently fixed and yet apparently adaptive characters of motile highly individuated animals. The doctrine of the continuity of the germ plasm is likewise the outgrowth of the study of highly individuated animals in which the various organs are early differentiated in the dividing egg. No one of the doctrines is wholly tenable; no one is more than a partial truth. Each appears to have arisen from a recognition of certain more or less unconsciously. selected and uncritically interpreted phenomena by each of several men 
who secured different facts and attempted explanations.

In a few animals the "germ plasm" may be morphologically early differentiated and reasonably continuous, though governed by the same laws as other tissues. In others, any part of the general tissues may give rise to a complete organism. The behavior of some organisms is intelligent and purposeful, while that of others is largely mechanical. Some structural responses of sessile organisms are advantageous, some indifferent and some harmful. Some of the more fixed structures of the highly individuated animals are advantageous, some indifferent, and some disadvantageous (Metcalf, '13). No other type of general statement appears to be tenable, yet each extreme of each proposition has at some time or other been the subject of some all-inclusive doctrine.

Such are the limitations of an individual's knowledge and the psychic limitations of our race and generation. In considering the psychology of religion, Ames ('10, p. 394) points out similar well-recognizable tendencies in that field of human activity and quotes Cooley on social development as follows:

Much energy has been wasted or nearly wasted, in the exclusive and intolerant advocacy of special schemes-single tax, prohibition, state socialism and the like, each of which was imagined by its adherents to be the key of millennial conditions. Every year makes converts to the truth that no isolated scheme can be a good scheme, and that real progress must be advanced all along the line.

Advance all along the line is ivhat biological science must achiere. This I believe means the encouraging of all lines of indirect attack, whether they at first throw light on the ideal central question of pure science or important practical problems or not. It means the exercising of extreme caution in the application of criteria of values to scientific results. Such measures tend not only to stifle the best initiative in good investigators, but also tend to check the building up of fruitful hypotheses. The latter danger is greatest in connection with the mechanistic criterion referred to above. As has already been stated, criteria of values can be safely applied only 
as broad general guides, and investigation should be measured on the basis of its thoroughness, the originality shown, etc.

In science special schemes of course do not exist recognized as such, but intolerant application of criteria of values results in essentially the same condition. One often hears the statement made by so-called scientific men, that this or that line of investigation has been pursued for several years, but has failed to yield important advances or generalizations, but they add, we will be very glad to recognize it as soon as its value is proven. This seems to us to be a distinctly unscientific attitude, and but a polite modern statement of a spirit which in former generations often sent men to the stake or dungeon. This is true because to these polite objectors its value is rarely or never proven. It is "schemes" (preconceived theories) thus presented that have in the recent past stifled the study of responses by discouraging efforts in that direction and thus contributed materially toward making zoology the unorganized science which it is to-day. We must recognize that the various aspects of zoology pure and applied have never been well correlated, less so we believe than in any other branch of natural science, clearly less than in botany. In general. animal physiology has been isolated in medical schools and genetics, faunistics and morphology have not been properly influenced by it, while morphologists for many years held themselves aloof from other workers.

In a discussion dealing mainly with the doctrine of natural selection in the origination of adaptations, Mathews ('13) has sounded the keynote of a growing attitude toward all response questions. Out of the infinite different combinations which may enter into the proteid molecule and the varying rates at which metabolic action may go forward, innumerable types of irritability and correlated structure have been and still are arising under the influence of environment external and internal. Of these some are incompatible with life, others indiffer- 
ent, and others advantageous. Upon these physiological character's natural selection has operated to eliminate, and with time has perhaps rendered of less frequent occurrence, those characters that are incompatible with their conditions of existence. External form, color ornamentation, etc., while no doubt often of importance themselves are more often the advantageous or indifferent correlatives of physiological or irritability types which are compatible with their conditions of existence. The study of irritability and response may be pursued in many ways-by experiment, by observation in nature alone or combined with experiment. The mapping of stimulating conditions in nature, of the distribution of types of irritability and response, which is one function of field ecology and modern geography, can hardly fail to contribute materially to the advance of knowledge in many lines, including that of the physico-chemical mechanism of life. The student of experimental ecology has an infinite field of problems and methods thrown open to him by the organization 'of such information relative to responses. Still in our attempt to make advances along the line of the study of responses, we must not forget that it is but one of several lines of advance, all of which must sooner or later be correlated with a view to broader generalization.

Hull Zoological Laboratory,

UNIVERSITY OF CHICAGO,

April 1, 1914

\section{LITERATURE CITED}

Adami, J. G. ('08). Principles of Pathology; Vol. I, General Pathology. Philadelphia.

Adams, Chas. C. ('13). Guide to the Study of Animal Ecology. Chaps. VIII, IX. New York.

Ames, E. S. ('10). The Psychology of Religious Experience. New York. Bateson, W. ('13). Problems of Genetics. New Haven.

Brooks, W. K. ('93). Salpa in its Relation to the Evolution of Life. Johns Hopkins Univ. Studies. Bicl. Lab., Vol. 5, pp. 129-211.

Child, C. M. ('04). Studies on Regulation, II. Jour. Expt. Zool., Vol. II, pp. 95-133.

('11). A Study of Senescence and Rejuvenescence Based on Experiments with Planaria dorotocephala. Roux. Arch., XXXI, pp. 537-616. 
('13). Certain Dynamic Factors in Experimental Reproduction. Roux. Arch., Bd. XXXV, pp. 598-641.

Coulter, J. M. ('09). The Theory of Natural Selection from the Standpoint of Botany. Fifty Years of Darwinism, pp. 56-75.

Cowles, H. C. ('11). A Text-book of Botany. Vol. II, Ecology. New York.

Cope, E. D. ('96). Primary Factors of Organic Evolution. Chicago.

Davenport, C. B. ('91). Cristatella: The Origin and Development of the Individual in the Colony. Bull. Mus. Comp. Zool., Vol. 20, pp. 101-152.

Delage, Y., and Herouard, E. ('96). Les Vermudiens, Zoologie Concrete I. V. Paris.

Dungay, N. S. ('13). A Study of the Effect of Injury on the Fertilizing Powers of Sperm. Biol. Bull., Vol. XXV, pp. 213-260.

Forbes, S. A. ('80). Some Interactions of Organisms. Bull. Ill. St. Lab. Nat. Hist., III, pp. 3-18.

Goode, J. P. ('04). Human Responses to the Physical Environment. Jour. of Geography, III, pp. 333-343.

Goebel, K. ('00). Organography of Plants. Part I, English ed., Oxford. Harmer, S. F. ('01). Polyzoa. Cambridge Natural History, Vol. II, pp. $465-534$.

Herdman, W. A. ('04). Ascidians and Amphioxus, 1. c., Vol. VII, pp. $35-138$.

Herrick, F. H. ('05). The Home Life of Wild Birds. New York.

Hickson, S. J. ('98). On the Species of the Genus Millepora. Proc. Zool. Soc. London, 1898, pp. 241-257.

Holmes, S. J. ('07). The Behavior of Loxophyllum and its Relation to Regeneration. Jour. Expt. Zool., Vol. IV, pp. 399-418.

('11). Evolution of Animal Intelligence. New York.

Henderson, L. J. ('13). The Fitness of the Environment. AM. NAT., XIVII, pp. 105-115.

Jennings, H. S. ('06). Behavior of the Lower Organisms. New York.

Johnson, Myrtle, E. ('10). A Qualitative Study of the Development of the Salpa Chain in Salpa fusiformis runcinata. Univ. of Cal. Pubs. in Zool., Vol. 8, No. 7, pp. 145-176.

Johnstone, J. ('08). Conditions of Life in the Sea. Cambridge.

Klebs, G. ('03). Willkürliche Entwicklungsänderungen bei Pflanzen. Jena. Lillie, Frank R. ('13). The Mechanism of Fertilization. Science, N. S., Vol. XXXVIII, pp. 524-528.

Livingstone, B. E. ('13). Adaptation in the Living and Non-living. AM. NAT., XLVII, pp. 72-82.

Loeb, J. ('06). Dynamics of Living Matter. New York.

MacDougal, D. T. ('11). Organic Response. AM. NaT., Vol. XLV, pp. 5-40. Mast, S. O. ('11). Light and the Behavior of Organisms. New York.

Mathews, A. P. ('13). Adaptation from the Point of View of the Physiologist. Am. NAT., XLVII, pp. 90-105.

MeGee, W J ('96). The Relations of Institutions to Environment. Smith. Rep., 1895, pp. 701-711.

Merriam, C. H. ('90). Results of a Biological Survey of the San Fran- 
cisco Mountain Region and the Desert of the Little Colorado. North American Fauna 3.

Metcalf, M. M. ('13). Adaptation through Natural Selection and Orthogenesis. AM. NAT., Vol. XLVII, pp. 65-72.

Minchin, E. A. ('00). Sponge. Lankester's Treatise on Zoology, Part II. London.

Moore, H. F. ('08). The Commercial Sponges and Sponge Fisheries. Bull. U. S. F. C., 1908, pp. 403-511.

Motz-Kossowska, S. ('08). Quelques considerations a propos de Plumularia lichtensterni Mark Turn et les espèces affines. Arch. Zool. Exp. et Gen. Notes et Revue, 4, T. IX, pp. 55-59.

Packard, A. ('01). Lamarck the Founder of Evolution. New York.

Pütter, A. ('11). Vergleichende Physiologie. Jena.

Reighard, Jacob ('10). Methods of Studying the Habits of Fishes with an Account of the Breeding Habits of the Horned Dace. Bull. Bur. of Fish., XXVIII, 1908, pp. 1111-1136.

Ritter, W. E. ('11). The Controversy between Materialism and Vitalism. Can it be ended? Science, N. S., Vol. XXXIII, No. 847, pp. $437-441$.

Romanes, G. J. ('92-'97). Darwin and After Darwin. 3 vols. London.

Shelford, V. E. ('11a). Ecological Succession, I. Stream Fishes and the Method of Physiographic Analysis. Biol. Bull., Vol. XXI, pp. $9-35$.

('11b). Ecological Succession, II. Pond Fishes. Biol. Bull., Vol. XXI, pp. 127-151.

('11c). Physiographic Animal Geography. Jour. of Morph. (Whitman Vol.), Vol. XXII, pp. 551-618.

('11d). Ecological Succession, III. A Reconnaissance of its Causes in Ponds with Particular Reference to Fish. Biol. Bull., Vol. XXII, pp. 1-38.

('12a). Ecological Succession, IV. Vegetation and the Control of Land Communities. Biol. Bull., Vol. XXIII, pp. 59-99.

('12b). Ecological Succession, V. Aspects of Physiological Classification. Biol: Bull., Vol. XXIII, pp. 331-370.

Strassberger, E., Schenk, Noll F., and Schimper, A. W. F. ('03). A Textbook of Botany. Translation by Porter and Lang. London.

Stockberger, W. W. ('13). A Literary Note on the Law of Germinal Continuity. AM. NAT., XLVII, pp. 123-128.

Washburn, M. F. ('09). The Animal Mind. Chap. I. New York.

Weismann, A. ('91). '92, 2v. Essays upon Heredity and Kindred Biolog ical Problems. Authorized Translation. E. B. Poulton \& A. E. Shipley. Oxford.

('93). The Germ Plasm a Theory of Heredity. Translation by N. W. Parker \& H. Rönnfeldt.

Wilson, F. P. ('12). Cell Stimulation by Means of Prolonged Ingestion of Alkaline Salts. Biochemical Journal, Vol. IV, p. 162.

Wood, Jones F. ('07). On Growth Forms and Supposed Species of Corals. Prod. Zool. Soc. London, 1907, pp. 518-556.

('11). Coral and Atolls. London. 




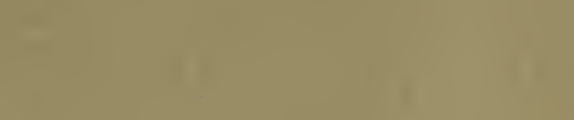

$=$

nit

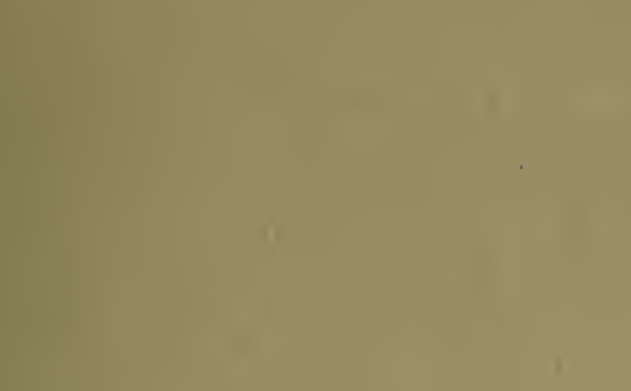

6.

$+1+2-1$

(1.)

- 1
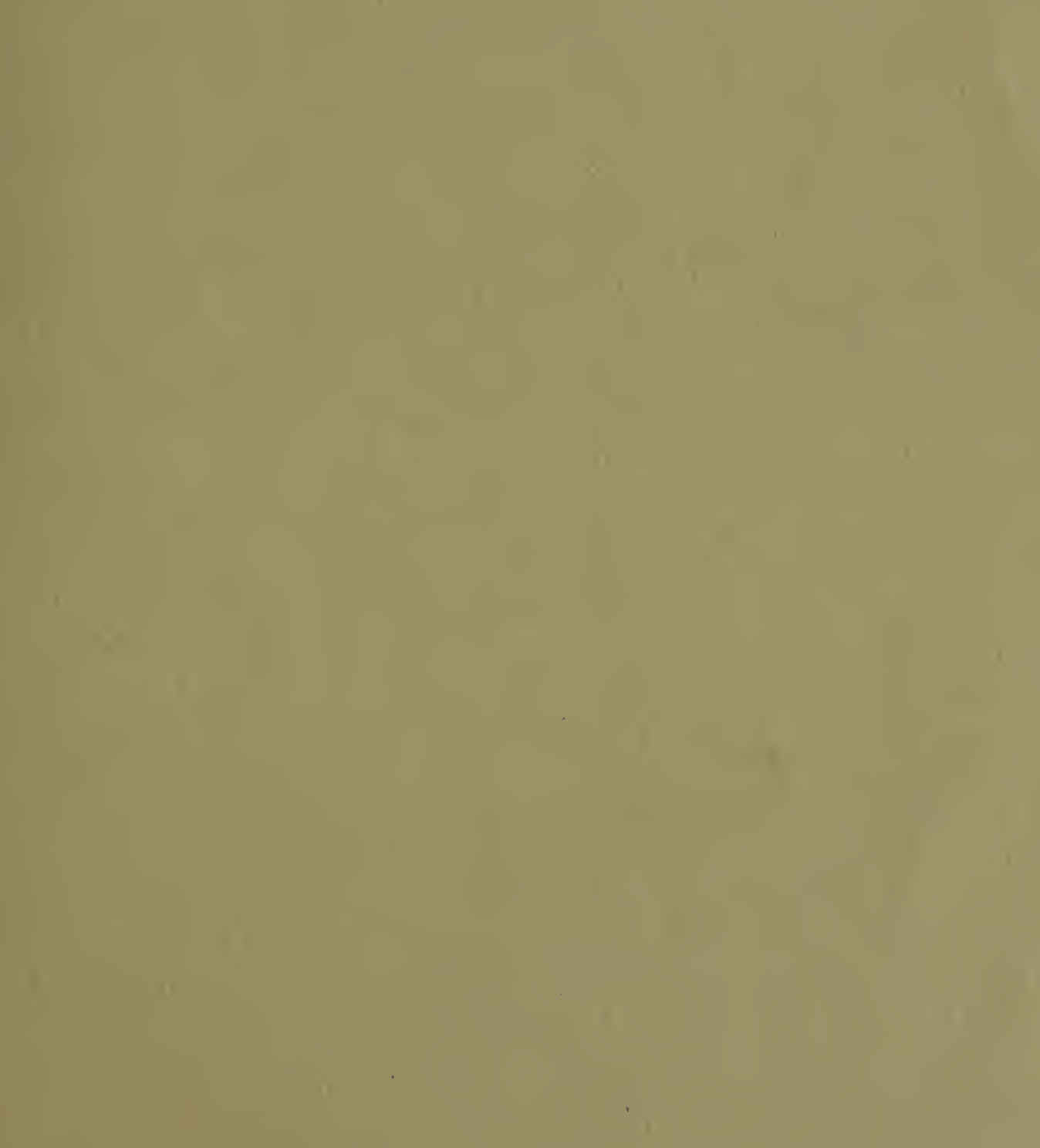
